ISSN: 0514-7336

DOI: http://dx.doi.org/10.14201/zephyrus201984207223

\title{
UNA EXCEPCIONAL LUCERNA DE BRONCE CON DECORACIÓN DE MÁSCARA TEATRAL DE COMPLUTUM (ALCALÁ DE HENARES)
}

\section{An exceptional bronze oil lamp with decoration of theatrical mask from Complutum (Alcalá de Henares)}

\author{
Sebastián Rascón Marqués* y Ana Lucía Sánchez Montes** \\ * Servicio Municipal de Arqueología. Ayto. de Alcalá de Henares. Camino del Juncal, s/n. 28802 Alcalá de Henares \\ (Madrid). Correo-e: srascon@ayto-alcaladehenares.es. ID ORCID: https://orcid.org/0000-0002-7835-3952 \\ **Arqueóloga profesional. C/ Salamanca, 42. 28523 Rivas (Madrid). Correo-e: aluciasmontes@gmail.com. ID ORCID: \\ https://orcid.org/0000-0002-6274-6735
}

Recepción: 28/11/2018; Revisión: 11/1/2019; Aceptación: 2/09/2019

\begin{abstract}
Resumen: Se presenta una excepcional lucerna plástica de bronce. El contexto arqueológico del que procede la pieza corresponde a una notable domus de la ciudad romana de Complutum que ha sido datada en el s. I d. C.; sin embargo, se ha podido constatar que varias de sus estancias fueron reutilizadas para la producción metalúrgica a partir del s. III d. C. El análisis de la pieza ha permitido definirla como una lucerna plástica de bronce plomado de buena calidad que cuenta con la representación de una máscara teatral, concretamente del 'esclavo listo' de la Comedia Nueva, imagen que se rastrea en otras producciones romanas. A través del estudio de este objeto se constatan las dificultades de la disciplina arqueológica a la hora de establecer tipologías universalmente reconocidas para las lucernas de bronce; sin embargo, se concluye que tipológicamente es posible detectar su vinculación con tipos descritos para talleres de la zona de la bahía de Nápoles. Se trata de una pieza excepcional que cuenta con escasos paralelos documentados en el mundo romano. Su fabricación parece corresponder a un momento situado a lo largo del s. I o comienzos del s. II d. C.; a pesar de ello, su uso debió continuar hasta fechas cercanas a finales del s. Iv. Todo parece indicar que se trata de una probable producción itálica.

Palabras clave: bronce romano; lucerna; decoración plástica; máscara cómica; producción itálica.
\end{abstract}

Aвsтract: We present an exceptional bronze plastic lucerne. The archaeological context from the piece corresponds to a remarkable domus of the Roman city of Complutum that has been dated to the $\mathrm{I}^{\text {st }}$ century AD; however, it has been observed that several of its rooms had been reused for metallurgical production from the III $^{\text {rd }}$ century AD onwards. The analysis of the piece has allowed us to define it as a good quality leaded bronze plastic lucerna that has the representation of a theatrical mask, specifically of the 'ready slave' of the New Comedy, whose image is traced in other Roman productions. Through the study of this object, the difficulties of the archaeological discipline in establishing universally recognised typologies for bronze skylights are confirmed; however, it is concluded that it is possible to detect their typological link with types described for the Bay of Naples workshops. It is an exceptional object with few parallels documented in the Roman world. Its manufacture seems to correspond to a moment located throughout the $\mathrm{I}^{\text {st }}$ century or the beginning of the $\mathrm{II}^{\text {nd }}$ century $\mathrm{AD}$; in spite of this, its use must have continued until near the end of the $\mathrm{It}^{\mathrm{th}}$ century AD. Everything seems to indicate this is a probable italic production.

Key words: Roman bronze; oil lamp; plastic decoration; comic mask; Italic production. 


\section{Introducción}

Laciudad hispanorromana de Complutum (Fig. 1) se localiza en la actual Alcalá de Henares (Madrid).
Fue una importante y bien conocida ciudad del centro de la Península Ibérica, ubicada en la vía que conectaba Augusta Emerita y Caesar Augusta. Entre 2010 y 2012 se realizaron trabajos arqueológicos de

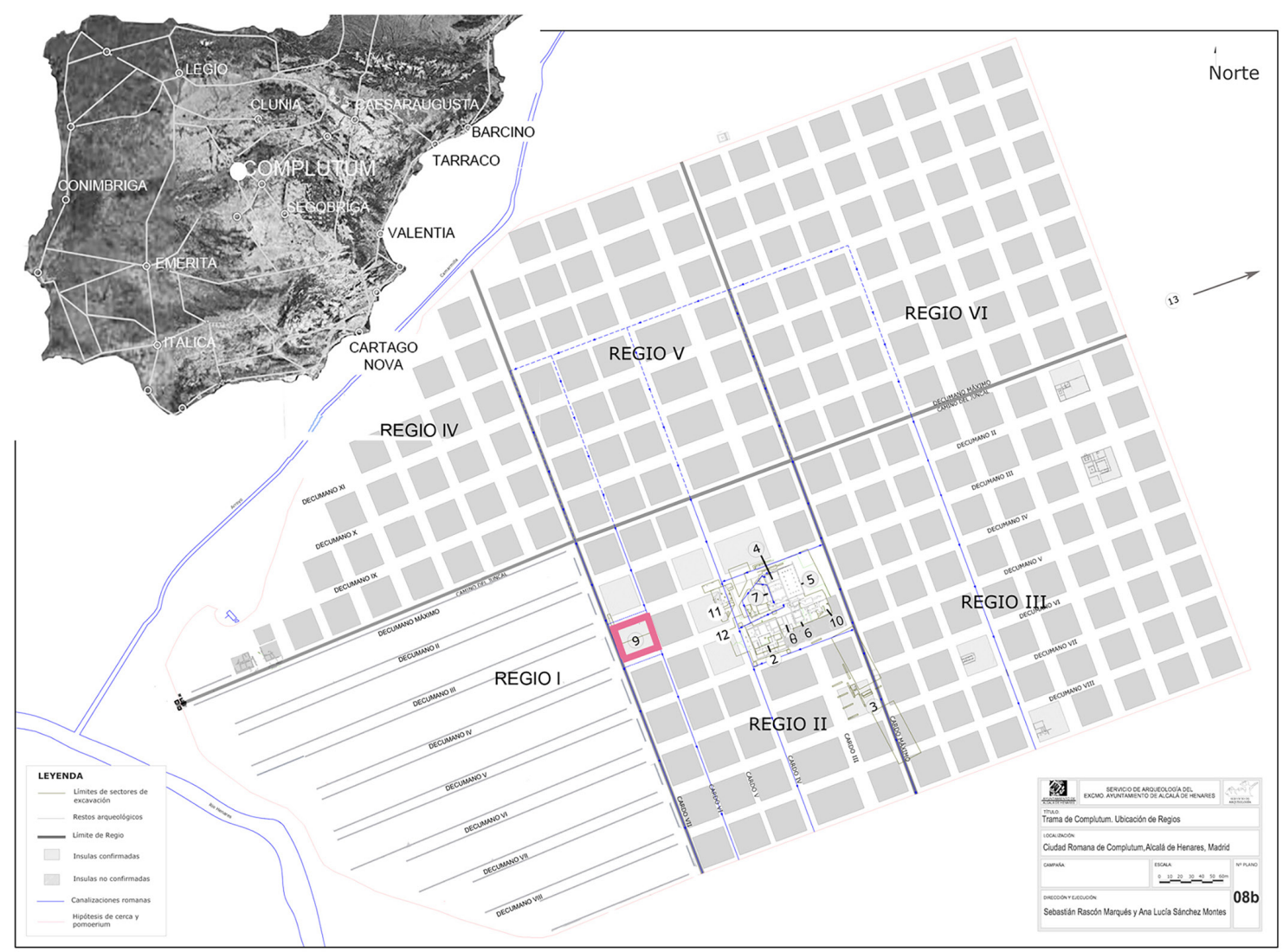

Fig. 1. Localización de Complutum en la Península Ibérica, en relación con algunas de las principales ciudades hispanas, y ubicación de la 'Casa de la Lucerna de la Máscara Teatral' en el trazado urbano complutense.

excavación y restauración en una de sus domus, la 'Casa de la Lucerna de la Máscara Teatral', durante los cuales se documentó el contexto arqueológico del que procede la pieza que presentamos. El objeto de nuestro trabajo es el estudio de esta excepcional lucerna, presentada en el marco del actual estado de conocimiento sobre las lucernas de bronce plásticas en general y, concretamente, en su marco hispano ${ }^{1}$.

1 Las excavaciones de la Manzana viI, desarrolladas bajo nuestra dirección, fueron financiadas por el Programa del 1\% Cultural del Ministerio de Fomento, la Comunidad de Madrid, el Consorcio Alcalá Patrimonio de la Humanidad y el Ayto. de Alcalá. La adjudicataria de la intervención fue la UTE Complutum y participaron en los trabajos de
Mientras el estudio tipológico de las lucernas cerámicas hispanas cuenta con un notable desarrollo (Morillo y Rodríguez, 2009), el relativo a las lucernas de bronce está mucho menos desarrollado. Fuera

campo L. Rodríguez, E. Zarco e Y. Peña. La restauración de la lucerna (sigla 5/1/1/CDIII/12/2042/3), imprescindible para la realización de este estudio, fue abordada por el Servicio Municipal de Arqueología del Ayto. de Alcalá y realizada por M. Corrada Solares. Agradecemos la colaboración del SECYR de la UAM y de su director, J. Barrios, que propiciaron el proceso de restauración durante el que se han realizado los análisis compositivos de la lucerna; estos serán objeto de un estudio específico posterior. En el momento de la redacción de este texto la lucerna se encuentra depositada en el Museo Arqueológico Regional de la Comunidad de Madrid. 
del ámbito hispano, para las lucernas en general y las de bronce en concreto, las grandes obras de referencia son la ya clásica de Loeschcke (1919), la de Menzel (1954) y la de Bailey (1996), que utilizan los grandes repertorios de Vindonissa, del Museo de Mainz y del Museo Británico respectivamente. También son fruto de la revisión de ingentes colecciones, en este caso las procedentes de yacimientos de la bahía de Nápoles, principalmente Pompeya y Herculano, las obras de Valenza Mele (1981), así como la De Spagnolis y De Carolis (1988) y la publicación colectiva sobre los materiales procedentes de estos yacimientos (Carandini, 1977). Esta dependencia de los grandes repertorios ha provocado la ausencia de una única tipología de las lucernas de bronce unánimemente admitida; cada investigador ha elaborado la suya que ha quedado condicionada por sus propios repertorios. Los problemas de clasificación, como se verá, se acentúan cuando abordamos la tipología de las lucernas plásticas, especialmente complejas porque son en realidad pequeñas obras de arte; es el caso de la que aquí presentamos, ya que son extremadamente originales, abiertas a la creatividad y, por tanto, difíciles de encuadrar en las tipologías existentes.

Para Hispania, donde el repertorio de lucernas de bronce es relativamente reducido, no existe aún una propuesta tipológica firme, aunque disponemos de la obra colectiva sobre bronces romanos derivada de la exposición organizada por el Ministerio de Cultura en 1990 (vv. AA., 1990), que supuso una actualización de conocimientos en general sobre estos materiales. Finalmente, citamos el gran trabajo de Pozo (1997: 204 y ss.) sobre las colecciones de la Bética que, si bien es un encomiable inicio para el material hispano, como el propio autor reconoce, presenta limitaciones metodológicas que dificultan su posible aplicación genérica.

\section{Contexto arqueológico: la 'Casa de la Lucerna de la Máscara Teatral' y la producción metalúrgica}

\subsection{La domus}

Englobada dentro de la Manzana viI (Fig. 2), esta casa responde al módulo característico del diseño urbano complutense (Rascón y Sánchez Montes, 2017: 128 y ss.). Se estructura en tres unidades de vivienda diferenciadas, donde la 'Casa de la Lucerna de la Máscara Teatral' ocupa una superficie de $30 \times 15$ m correspondiente a la mitad meridional de la manzana (Sánchez Montes, 2014)². Aquí nos centraremos exclusivamente en el contexto de producción metalúrgica constatado en ella, documentado en la Fase 2.

La casa fue construida a mediados del s. I d. C., pero en el s. III se produjeron varias rehabilitaciones en las que, entre otras cosas, se desarrollaron en las Estancias 41-50, 53-54 y 43 hasta tres probables talleres metalúrgicos con funcionamiento coetáneo (Fig. 3). Esta nueva finalidad se ha constatado a partir de las infraestructuras documentadas in situ: en 53-54, un modelo arquitectónico de sala -54 - más antesala -53-; en la primera se excavó un último nivel de uso -UE 2478/2429- formado mayoritariamente por cenizas, además de dos hornos de reducción -UUEE 2425 y $2427-$. La recuperación en este nivel de una torta de bronce, que ha de considerarse materia prima, constata que se realizaron también trabajos de moldeado de bronce. Por su parte, en la Estancia 43, vinculada a otros dos ambientes de uso comercial con los que mantiene paso abierto -51 y 44 , este último con acceso desde la calle-, se ha constatado un último nivel de uso -UE 2126/2139- formado por ceniza y carbón y conectado con tres estructuras negativas de combustión -UUEE 2185, 2187 y 2135-que deben interpretarse como pequeños hornos de reducción.

La constatación arqueológica de esta actividad industrial se refuerza mediante la aparición de algunos bronces singulares reconvertidos en materias primas en estos contextos: una base de lampadario de bronce en forma de flor de loto en la Estancia $43 \mathrm{y}$, en sus inmediaciones, un dedo pulgar y una mano de bronce procedentes del despiece de estatuas de gran tamaño, así como el fondo y el asa de un cuenco. Además está el conjunto en que se encontró la lucerna en la Estancia 50.

2 Cf. especialmente la tesis doctoral de A. L. Sánchez Montes: La casa urbana privada en la ciudad romana de Complutum, presentada en 2017 en la Univ. Autónoma de Madrid. 


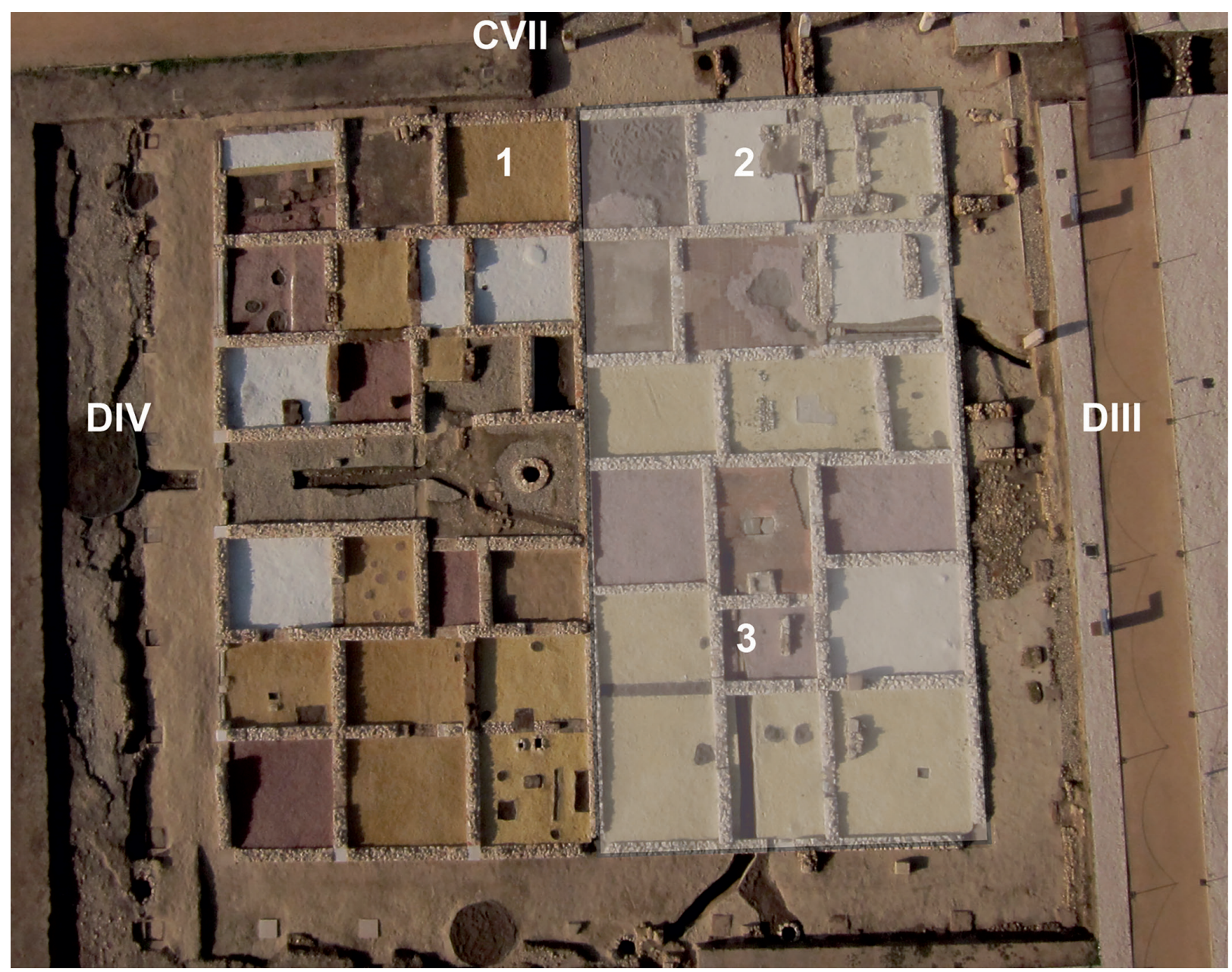

Fig. 2. Vista aérea de la Manzana VII, mostrando los decumanos -III y IV-y cardos -VI y VII- a su alrededor, así como las tres domus que contiene: 1) Casa de la Lucerna de la Máscara Teatral; 2) Casa de Marte; 3) Casa del Atrio.

Se ha documentado también un taller metalúrgico en la Estancia 34, si bien se encuadra en la Fase 1, por lo cual no se puede considerar coetáneo a los ya referidos.

\subsection{La Estancia 41-50}

La lucerna que presentamos acompañaba a un conjunto de objetos metálicos relacionados con el último nivel de uso de la Estancia 50 (Fig. 4). Con unas dimensiones ${ }^{3}$ aproximadas de $3 \times 3,30 \mathrm{~m}$, esta

3 Las medidas de superficie se ofrecen indicando, en primer lugar, la longitud del eje N-S y, a continuación, la del eje E-O. era una antesala unida a una sala, la Estancia 41, de 4 x 3,30 m, ambas conectadas mediante un vano de 1 $\mathrm{m}$. A estas estancias se accedía desde un distribuidor, la estancia 49, conectado a su vez con el vestíbulo.

El conjunto de bronces se encontraba en el relleno -UE 2042- de una pequeña cubeta -UE 2043-, en relación con el último nivel de uso sin que haya sido posible identificar pavimento alguno. Este lote formaba un paquete de forma que el cuenco, multifragmentado, parecía contener en su interior el resto de los fragmentos de bronce y la propia lucerna; esto se afirma con las debidas precauciones marcadas por el hecho de que el conjunto se había cohesionado a causa de las numerosas corrosiones e impurezas (Fig. 5). 


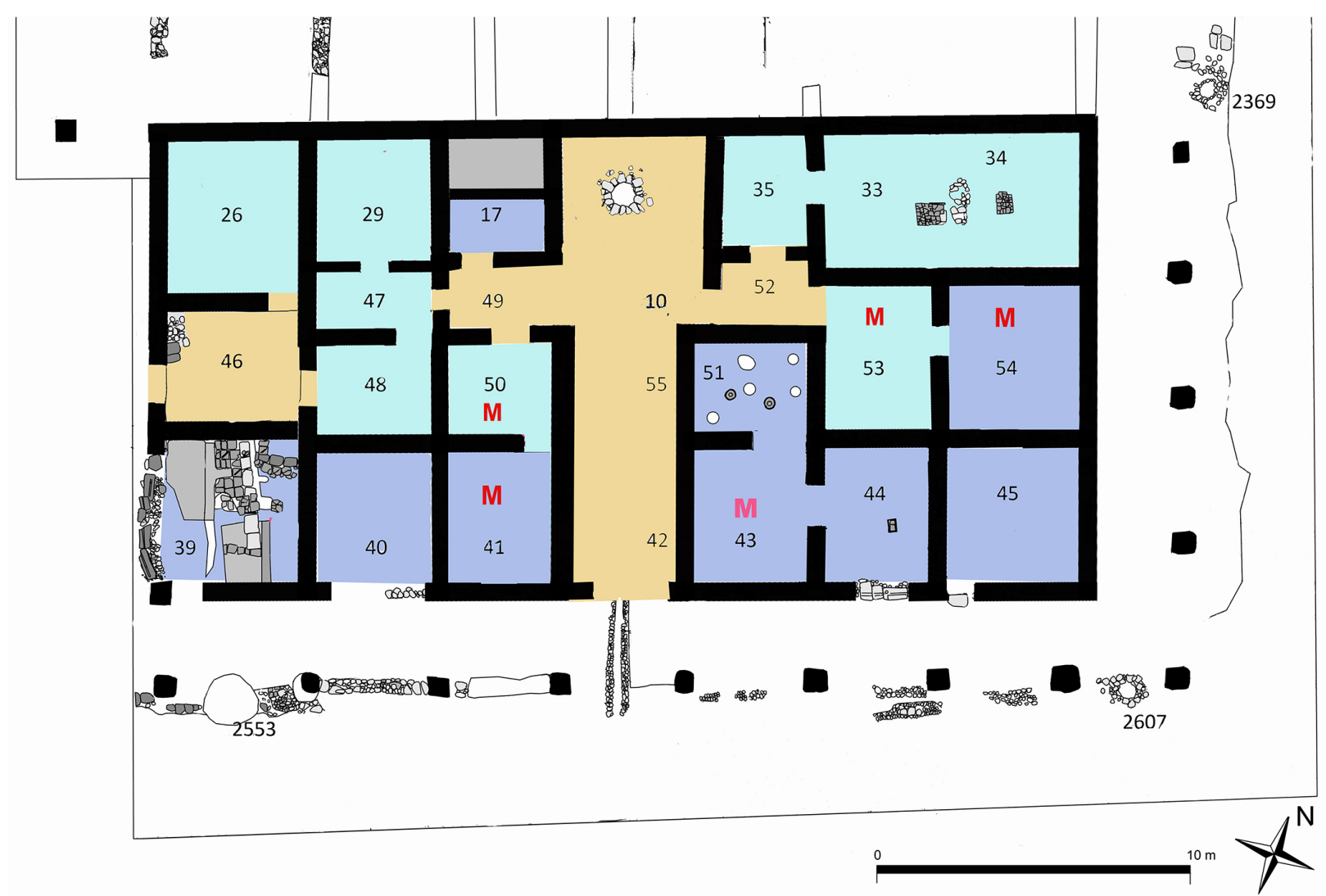

Fig. 3. Planta general interpretativa de la Fase 2 de la Casa de la Lucerna de la Máscara Teatral: M) espacios destinados a la metalurgia en esta fase.

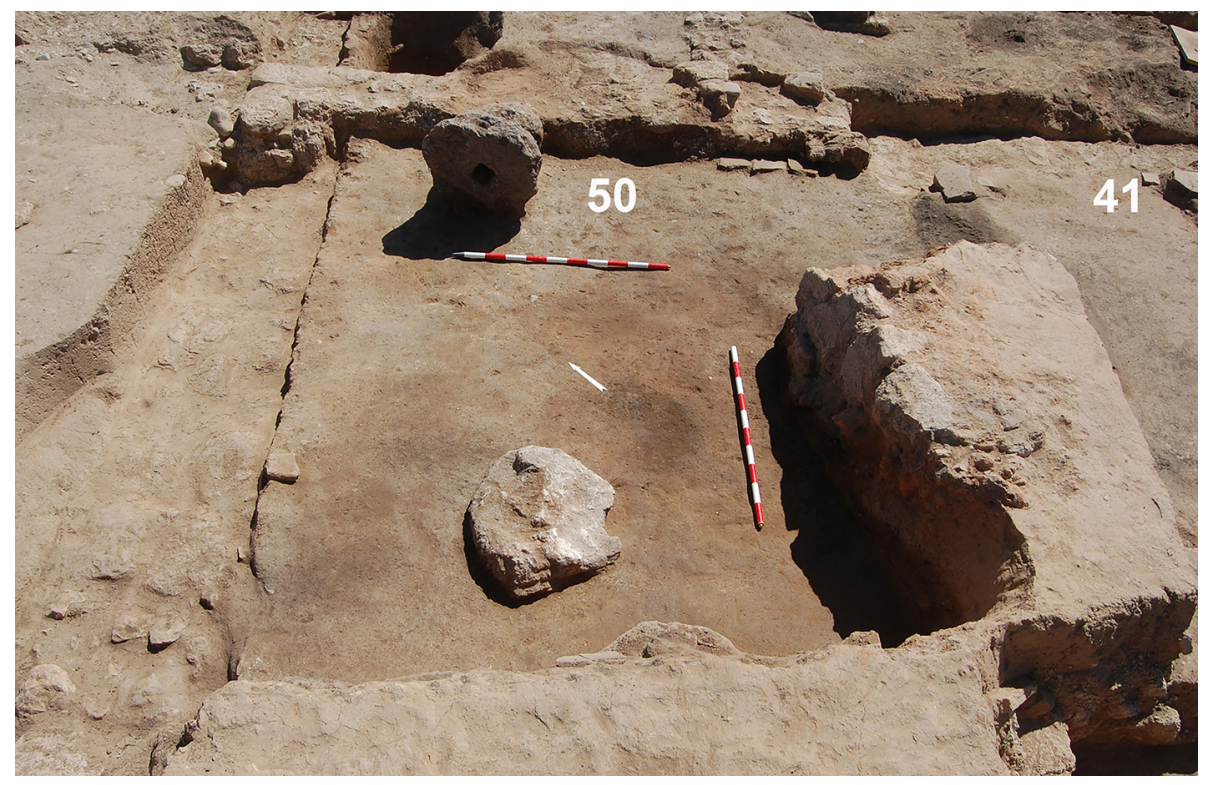

FIG. 4. Vista general de la Estancia 50, desde el O, antes de la excavación de la cubeta UE 2043, indicada con una flecha.
No existen materiales directamente vinculables a la estratigrafía de las últimas fases de la Estancia 41-50. Sin embargo, el último nivel de uso de las Estancias 29 y 47 -UUEE 2121 y 2128-, sellado por una serie de niveles de derrumbe, proporciona datos relativamente precisos del abandono del edificio. Así se ha podido constatar una cronología de la segunda mitad del s. IV o del v gracias a un pequeño ajuar doméstico en el que destaca una pareja de cuencos de sigillata 


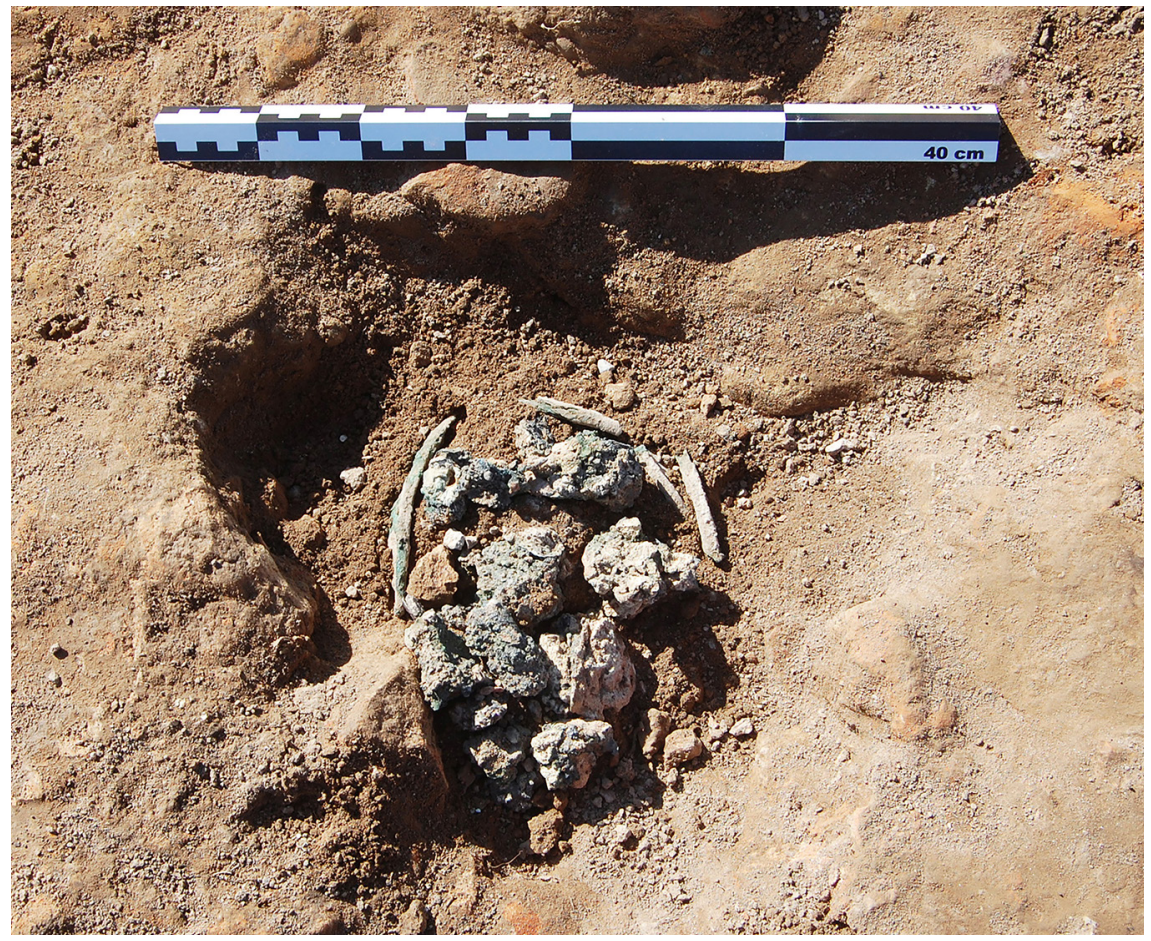

FIG. 5. Excavación del conjunto de bronces en el interior de la pequeña cubeta UE 2043.

\section{La lucerna}

\subsection{El conjunto de bronces}

Parece evidente que el conjunto de bronces -UE 2042- era un suministro de materia prima, es decir, un paquete de piezas amortizadas (Fig. 6). Teniendo en cuenta que habían perdido su función original -esto no lo podemos certificar en el caso de la lucerna, pero sí de las otras piezas-, necesariamente debe interpretarse como materia prima. $\mathrm{Su}$ finalidad, considerando las actividades metalúrgicas documentadas en esta casa, muy probablemente sería la fundición para obtener el material con que fabricar hispánica tardía 8, y un pequeño kalathos de cerámica pintada tardía que imita la forma 1 de la hispánica tardía. nuevos objetos mediante la técnica del moldeo. El conjunto estaba constituido por 52 fragmentos de láminas de bronce que, a falta de un estudio más

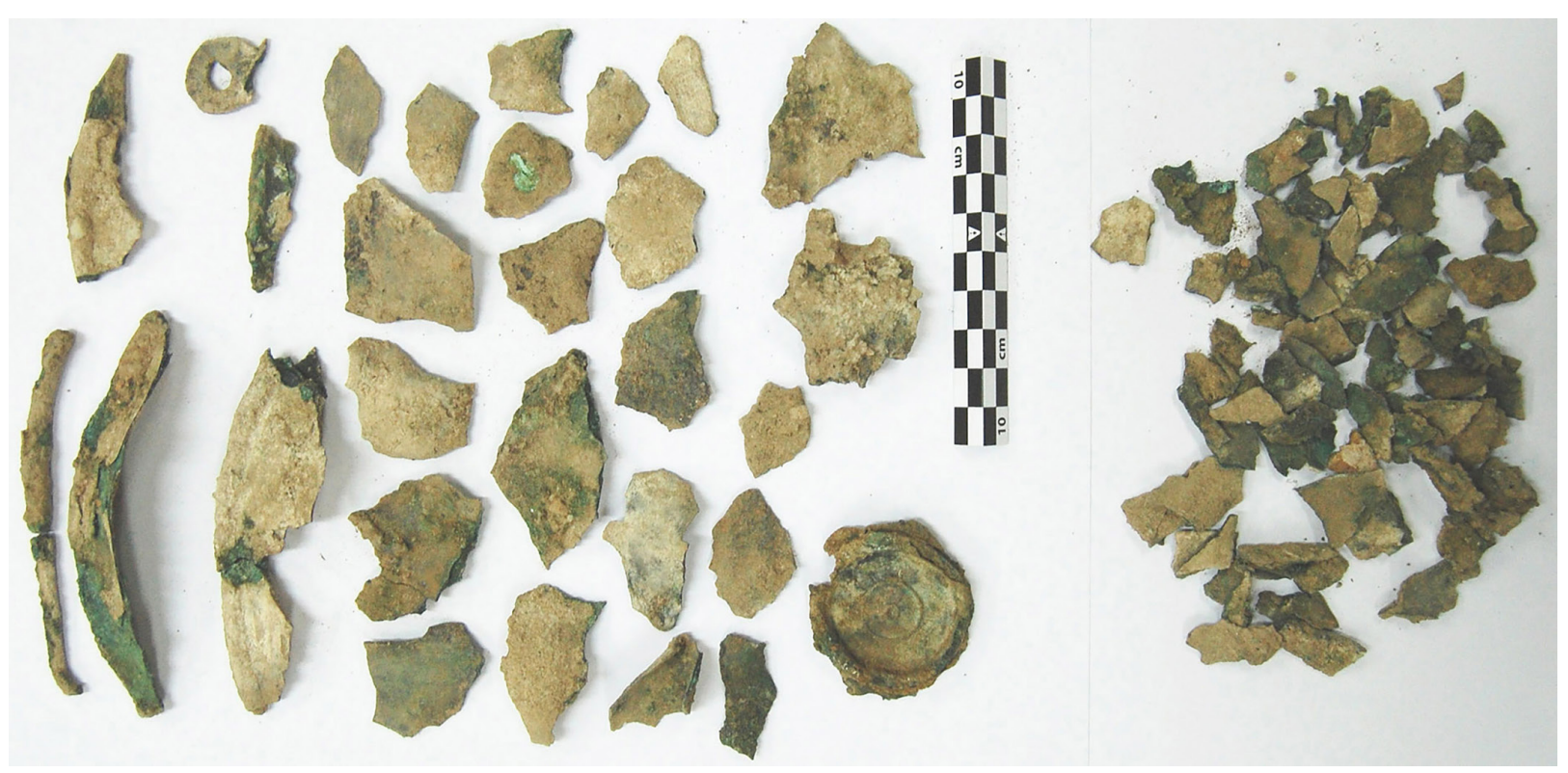

Fig. 6. Conjunto de fragmentos de bronce que acompañaban a la lucerna; a la izquierda de la escala, los restos del cuenco, acetre o calderito. 
detallado, corresponden todos o casi todos a un cuenco, acetre o calderito multifragmentado. Aún a falta de su restauración y estudio de detalle, esta pieza se encuadraría entre los Tipos 1-3 de Palol (1970), ampliados por Fuentes (1990), con perfil de fondo hemisférico y labio ligeramente exvasado y engrosado. Además había aproximadamente 40 fragmentos de una o varias piezas que no ha sido posible identificar, la lucerna que se presenta y un tubo de plomo.

\subsection{Descripción de la lucerna}

En el momento de su hallazgo la pieza no estaba fragmentada, aunque sí parcialmente incompleta, y presentaba graves alteraciones en lo que a su conservación se refiere: su superficie estaba cubierta casi completamente por productos de corrosión y carbonataciones en forma de malaquita, habiéndose adherido al cuerpo fragmentos del cuenco, de las cadenas que servían para suspenderla y de otros elementos minerales (Fig. 7). Se sometió, por ello, a una exhaustiva restauración, fruto de la cual es su aspecto actual. Las principales pérdidas detectables se encuentran en la parte trasera del infundibulum, junto a la unión con el asa, en la unión de la base del infundibulum con el rostrum y, sobre todo, en el pie.

Con motivo de la restauración se llevó a cabo el análisis compositivo mediante la técnica LIBS, realizado en la base de la lucerna, zona libre de concreciones ${ }^{4}$. Se observó la presencia de cobre $-88+9 \%-$, estaño $-8,5+1,4 \%-$ y plomo $-3,1$ $+0,6 \%-$; es decir, se trata de un bronce plomado

4 Son resultados aportados por J. P. Cid, responsable del análisis en el SECYR de la UAM, y recogidos en la correspondiente memoria de la restauración realizada por encargo del Servicio de Arqueología Municipal; cf. Corradas Solares, M.: Memoria técnica del tratamiento de restauración de dos piezas arqueológicas de aleación de base cobre pertenecientes al yacimiento de la ciudad romana de Complutum, Alcalá de Henares: lampadario: 5/1/1/CDIII/12/2122_2; lucerna: 5/1/1/ CDIII/12/2042/3. Alcalá de Henares, p. 31. Aún está pendiente un análisis en profundidad a partir de la colaboración de ambas instituciones.

(C) Universidad de Salamanca

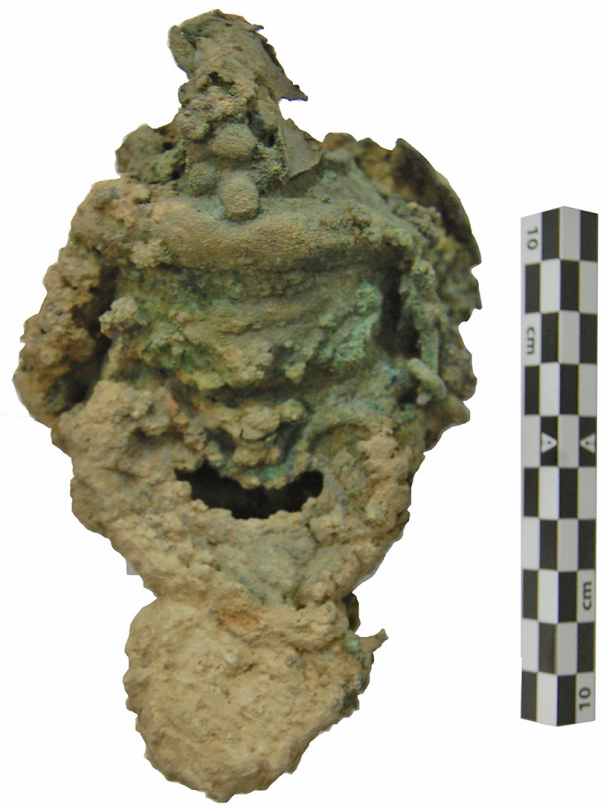

Fig. 7. La lucerna hallada en Complutum inmediatamente tras su aparición en el registro arqueológico.

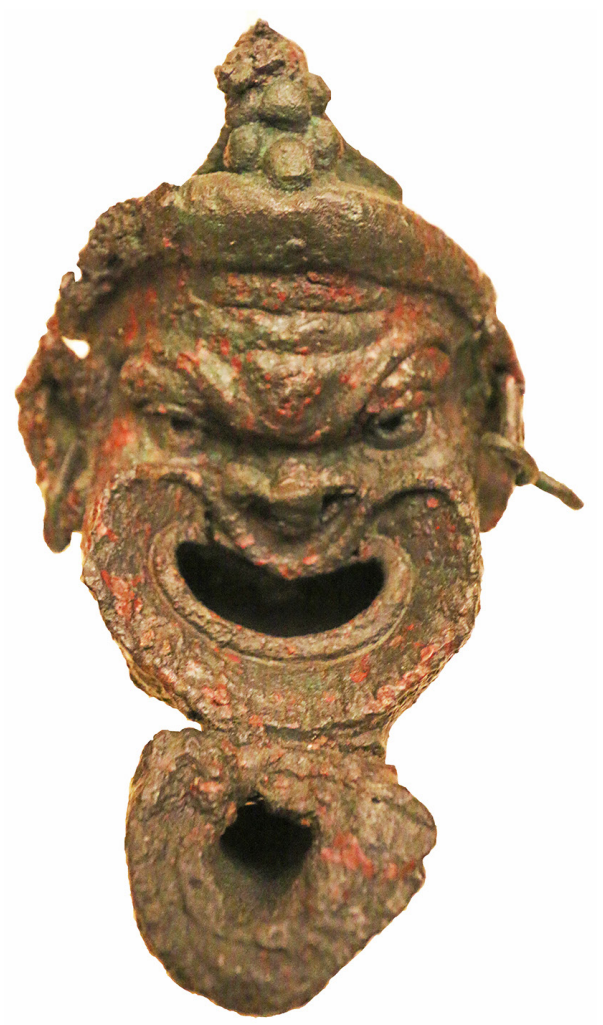

Fig. 8. Vista superior de la lucerna con representación de máscara teatral hallada en Complutum tras su restauración. 
con un porcentaje de plomo relativamente reducido. También se documentaron aluminio, calcio, magnesio y silicio, que el responsable del análisis atribuye al sustrato en el que estuvo enterrada la pieza o bien a inclusiones accidentales durante la manufactura de la pieza.

Las dimensiones generales de la lucerna son $12,62 \mathrm{~cm}$ de longitud, 7,20 $\mathrm{cm}$ de anchura y 7,65 $\mathrm{cm}$ de altura (Figs. 8-10). El grosor de la pared -medido en la boca de la máscara- es de $0,48 \mathrm{~cm}$. Su peso era de $698 \mathrm{~g}$ antes de la restauración. Con todas las precauciones inherentes a las tipologías de las lucernas, que se acentúan en las metálicas (Morillo y Rodríguez, 2009), nuestra pieza sería de tipo plástico, con el cuerpo principal o infundibulum resuelto con una representación tridimensional de una máscara teatral cómica, identificable con el personaje del 'esclavo listo' de la Comedia Nueva. Esta representación ha sido concebida para una observación principal, desde arriba de la propia pieza. En realidad, más allá de esta primera clasificación, y sin poder atribuirse a ningún tipo preciso de las diversas tipologías hasta ahora propuestas, esta lucerna tiene elementos rastreables en las mismas: el rostrum de tendencia triangular diferenciado del infundibulum recuerda a las lucernas de volutas, aunque estas no existen en nuestro caso. El depósito, en su vista superior, tiene un desarrollo circular semejante a las lucernas de disco, aunque este no aparece aquí pues queda oculto por el propio desarrollo de la máscara. En este sentido, evoca el tipo Loeschcke Ic, fechable en época neroniana o flavia, aunque se distancia del mismo por la adición del asa y el pie, ausentes en el tipo original.

Dispone de un asa vertical de forma ovoide, en la parte trasera, y al frente rostrum claramente diferenciado del infundibulum. Para alimentar de aceite el depósito se aprovecha la boca de la máscara, que tiene una abertura de 2,63 x 0,80 cm. La lamparita tiene un pie anular muy resaltado y con umbo central, con una altura de $0,85 \mathrm{~cm}$ y un diámetro de $4,35 \mathrm{~cm}$. Esto implica que podía autosustentarse en su propio pie, aunque también podía colgarse mediante tres cadenitas; de hecho, se conserva el primer eslabón de una de ellas en la oreja izquierda

(C) Universidad de Salamanca de la máscara, eslabón con una sección de $0,25 \mathrm{~cm}$ y una longitud de $1,92 \mathrm{~cm}$. El arranque de un segundo eslabón se conserva en la oreja derecha y un tercero se percibe en la cima del asa.

Sobre esta estructura general -la clásica de una lucerna romana-, ocupando toda la parte superior del depósito y la unión de este con el asa, se localiza la máscara que pasamos a describir: con nariz chata y gruesa, baja las cejas y las juntas sobre ojos penetrantes que se fijan en el espectador, mientras la boca se abre desmesuradamente en una sonrisa exagerada. Esa sonrisa, que se aprovecha como orificio de alimentación, ofrece una expresión que, a partir del Sistema de Codificación Facial -Facsdesarrollado por varios autores (Freitas-Magalhães, 2017), puede calificarse de enfado, maldad o inteligencia perversa. Los ojos están trepanados. Alrededor de la boca, una banda en la que se representa una barba, donde, aun estando el relieve bastante perdido, se perciben líneas incisas y protuberancias que representarían el pelo, y que probablemente se realizaron en el mismo moldeado. A ambos lados, se desarrollan sendas orejas en las que, como si se tratase de pendientes, se insertan los eslabones de dos de las tres cadenas para suspender la pieza. La oreja izquierda muestra la intención del escultor de darle forma levemente picuda. La máscara, en su parte superior, estaba delimitada por una especie de visera o flequillo de sección ovalada, en relación con los característicos peinados que presenta este tipo de

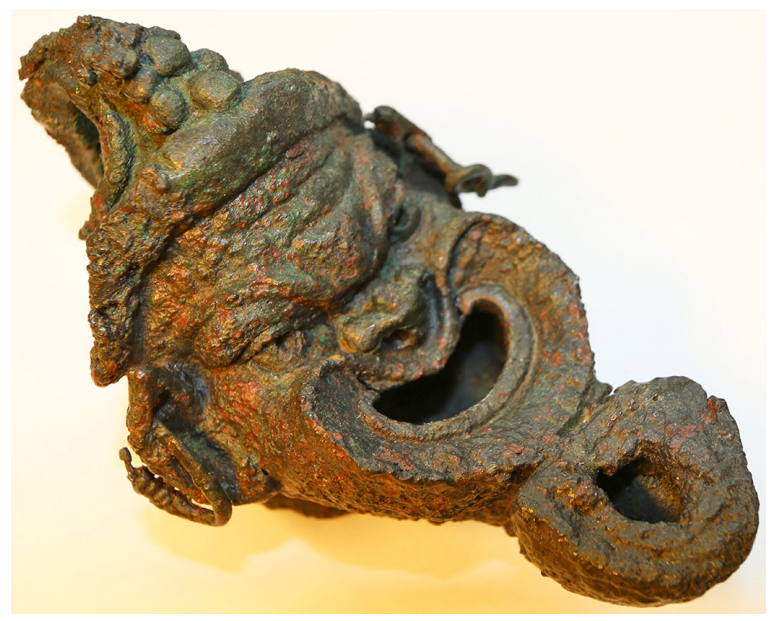

FIG. 9. Lucerna plástica de bronce, vista con perspectiva. 


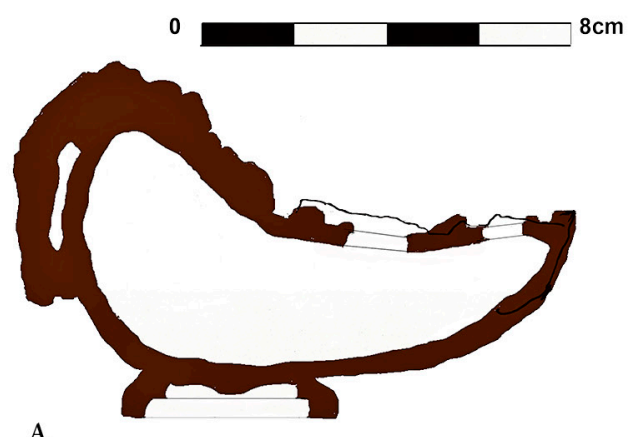

A

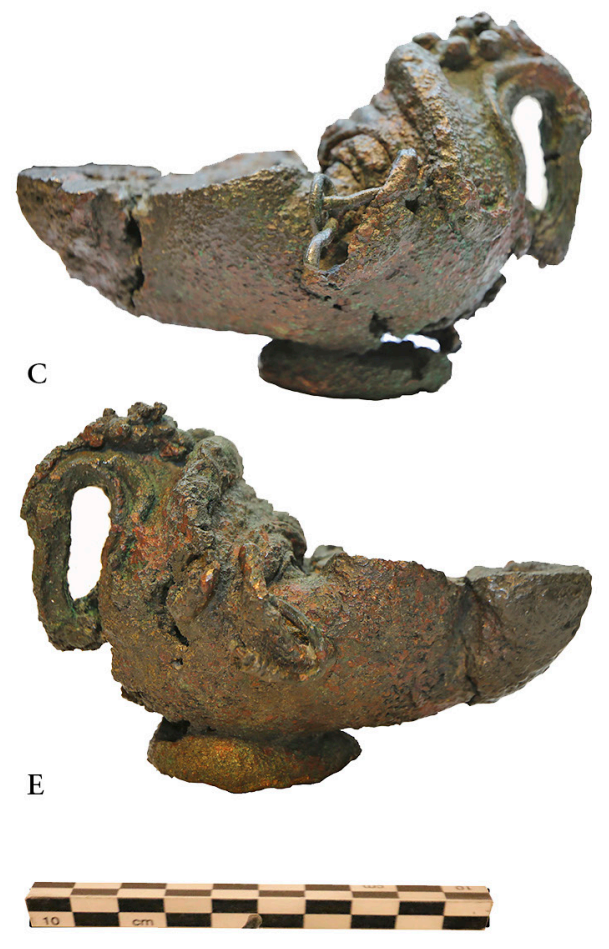

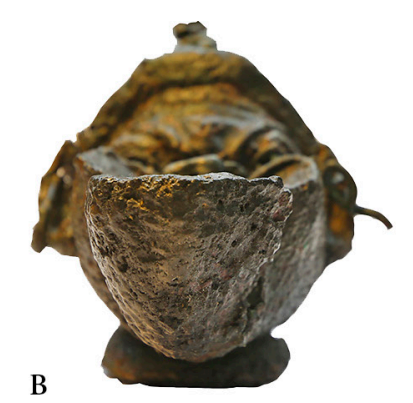
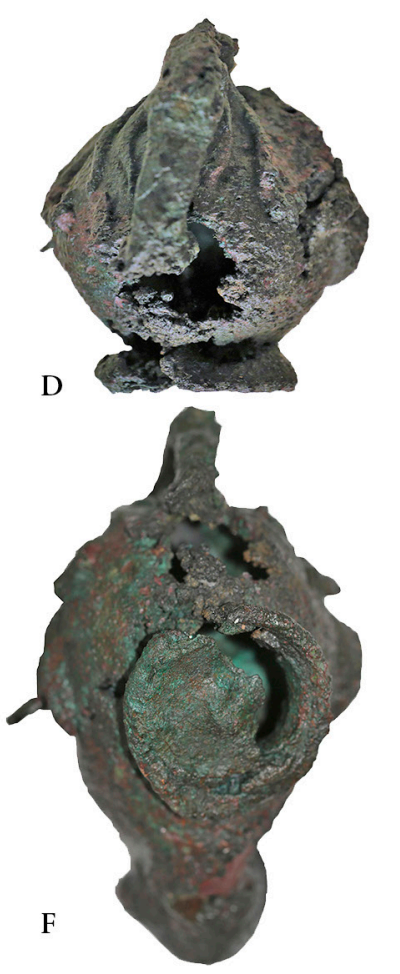

FIG. 10. Lucerna plástica de bronce de Complutum tras su restauración: A) sección longitudinal; B) vista frontal; C) lateral izquierda; D) trasera; E) lateral derecha; F) inferior.

personajes en todo tipo de soportes iconográficos. Sobre la visera y ocultando la unión con el arranque del asa se siguen desarrollando los motivos esculpidos, concretamente un pequeño racimo de uvas y tallos de vid, dos de los cuales se extienden por la parte posterior del infundibulum, mientras un tercero corre a lo largo del asa, proporcionando una sensación de unidad a toda la pieza.

El asa está integrada en una sola pieza con el infundibulum. De sección maciza y ovalada, se dispone verticalmente y es ovoide, con la parte más

(C) Universidad de Salamanca

ancha en la zona alta. Desgraciadamente, la unión de la parte inferior con el infundibulum está muy deteriorada y con importantes faltas de material. Por el contrario, la unión de la parte superior está totalmente integrada en el depósito mediante la decoración de frutos y tallos de vid que se superpone sobre los dos elementos funcionales.

Diferenciado de la máscara, al frente se desarrolla el rostrum, con una longitud de $2,85 \mathrm{~cm}$, cuya planta se aproxima a un triángulo de Reuleaux, con la correspondiente abertura para la mecha de $1,15 \mathrm{~cm}$ de diámetro. Los bordes del rostrum estaban marcados con dos molduras parcialmente perdidas.

La pieza se fabricó a molde, mediante la técnica de la cera perdida. Existió algún proceso de retoque postmoldeado probablemente, al menos, en la barba y en los ojos.

\subsection{Estudio}

Aunque no se dispone de una sola tipología para lucernas de bronce sino las elaboradas a partir de las colecciones analizadas por diferentes investigadores, podemos, sin embargo, concluir que aquella en la que mejor podría encuadrarse nuestra pieza es la de Valenza Mele, basada en los extensos repertorios de los yacimientos de la bahía de Nápoles. Dentro de ella se encuadraría en el grupo de las lucernas atípicas y plásticas, concretamente en la Categoría 19, es decir, las lucernas con cabeza humana o máscara (Valenza Mele, 1981: 152 y ss.). La pieza de Complutum pertenece a la tradición de lámparas de bronce plásticas de alta calidad que, en 
ocasiones, adquirían una elaborada morfología convirtiéndose, de hecho, en pequeñas obras de arte. Estas lucernas eran realmente objetos de lujo, escasos y refinados y, como ha señalado Erice (2004: 207), en contextos arqueológicamente muy generosos, como Pompeya “... se encontraban en las viviendas de la ciudad de cierto nivel económico y social. Los ambientes dedicados a recibir a los clientes y a las visitas [...] es donde parecen concentrarse estos elementos". Incluso así eran objetos relativamente escasos en comparación con el resto de los ajuares domésticos.

Este tipo de lucernas representaba, entre otros motivos, personajes de la cultura popular, el mito o la literatura. Estas producciones de gran plasticidad, que representan temas que también aparecen en lucernas cerámicas de calidad inferior, se remontan al s. III a. C. y al gusto helenístico desarrollado en el ámbito greco-oriental; sin embargo, a partir del s. I a. C. y a lo largo de todo el s. I y la primera mitad del s. II d. C., tuvieron un notable desarrollo y difusión por toda la geografía romana.

La buena calidad de nuestra lucerna es evidente a partir de sus características formales y estéticas. Los análisis compositivos inciden en una elevada presencia de cobre y estaño, frente a un reducido porcentaje de plomo, pese a lo cual debe seguir considerándose un bronce plomado, habitual en la producción de objetos de bronce en el mundo romano. Los estudios arqueometalúrgicos tienen un desarrollo todavía limitado en la investigación de los bronces romanos y apenas se han aplicado a las lucernas y especialmente a las hispanas; sin embargo, existen algunas investigaciones puntuales pero muy serias en esta línea, como las realizadas para los bronces de Camino de Santa Juana (Montero, 2015), también en el mismo ámbito geográfico complutense; para varios bronces de la Meseta Sur (Aurrecoechea, 2009); o sobre ajuares funerarios de Complutum, en su mayoría tardoantiguos (Rovira et al., 1989).

El personaje representado en el caso complutense corresponde al 'esclavo listo' que, con un rostro pícaro, avejentado, inteligente e intrigante, es protagonista de la Comedia Nueva, y que corresponde al n. ${ }^{\circ} 22$ del repertorio de personajes teatrales

(C) Universidad de Salamanca presentado en el Onomasticon de Iulius Pollux, escritor alejandrino del s. II d. C. Debe recordarse que las máscaras teatrales responden a un estereotipo, $y$ que, dada su propia función, representaban gestos caricaturizados que ayudaban a la transmisión de los contenidos cómicos o trágicos de las obras y a caracterizar a los personajes. Al mismo tiempo, se reconoce también a estos un valor mágico y simbólico, ligado al mundo dionisiaco. De hecho, en algunos casos representaciones parecidas a las nuestras se interpretan no como máscaras teatrales, sino como silenos, siendo muchas veces difícil discernir con precisión a unos de otros, aunque en la práctica hay criterios, como la presencia en la representación de silenos, de grandes orejas picudas. En cualquier caso, lo dionisiaco y lo teatral en el mundo clásico están firmemente ligados.

Por unas y otras razones los 'esclavos listos', y siempre con una aproximación a lo dionisiaco, fueron personajes muy arraigados en la cultura popular del s. I d. C. y, sin duda, en la posterior, lo que motiva su presencia en representaciones artísticas sobre diversos soportes, bien solos o bien formando parte de escenas que ilustran temas teatrales, probablemente comedias concretas, pero que no podemos identificar: apliques de bronce, como el del Museo de Split con n. ${ }^{\circ}$ inventario H 3504 (Cargo, 2002: 176) o el de Baelo Claudia conservado en el MAN de Madrid, con n. ${ }^{\circ}$ de inventario 26/15/72 (vv. AA., 1990: 183). Pero aparecen también en mosaicos como, por ejemplo, en el mosaico de Máscaras Teatrales ${ }^{5}$ conservado en el Museo Capitolino de Roma, con n. ${ }^{\circ}$ de inventario MC0392. Entre la pintura mural está la escena de comedia del atrio de la 'Casa de Casca Longus' de Pompeya (Fig. 11), un atrio decorado enteramente con pequeñas escenas de tema teatral. Incluso está presente en escultura, por ejemplo, en el relieve de la pieza que probablemente es un pynax con escena teatral de la colección Farnesio, hoy en el Museo Arqueológico Nacional de Nápoles.

La relevancia de la pieza complutense aumenta si la contextualizamos entre las lucernas de bronce

5 http://www.museicapitolini.org/es/percorsi/percorsi_per_sale/palazzo_nuovo/sala_delle_colombe/mosaico_ con_maschere_sceniche.

Zephyrus, LXXXIV, julio-diciembre 2019, 207-223 


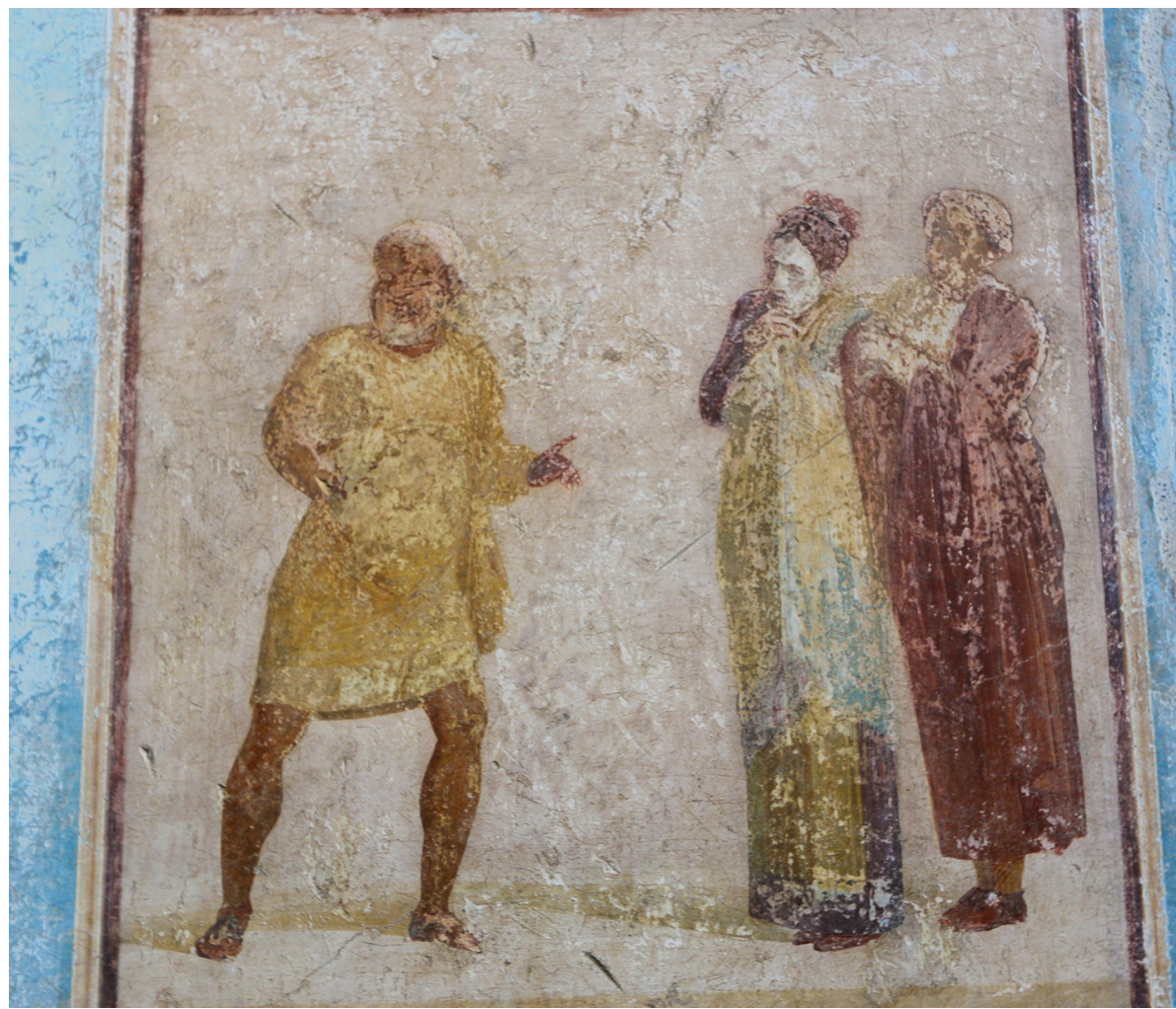

FIg. 11. Pintura mural con escena de comedia del atrio de la 'Casa de Casca Longus' de Pompeya.

halladas en la Península Ibérica ya que son relativamente escasas y, más aún, las encuadrables en el tipo de las plásticas. Además del catálogo sobre bronces romanos en España, fruto de la exposición celebrada en Madrid en 1990 (vv. AA., 1990), desde la que han transcurrido casi 30 años de intensa actividad arqueológica española, hoy existen dos trabajos de referencia que recogen la bibliografía existente sobre estos hallazgos en Espańa y Portugal: uno dedicado a la metalistería hispanorromana en el que se recopilan los objetos para iluminación identificados en territorio español (Fernández Ibáñez, 2007: 667) y otro que lo hace para Portugal (Nunes, 2002).

Las relativamente frecuentes lámparas piriformes, asimilables a los tipos Loeschcke XX y XXI o al tipo vi de Pozo, tipológicamente presentan un pie y el rostrum tiende a buscar la forma triangular diferenciándose del depósito cóncavo; estos elementos son semejantes en la pieza complutense que, sin embargo, se aleja de ellos en la forma del depósito.
Los tipos citados no son lucernas plásticas, aunque se caracterizan por presentar una decoración concentrada en el remate del asa, que es curva. Frecuentemente, esa decoración consiste en una máscara teatral resuelta en dos dimensiones; suele ser la máscara de la tragedia, la musa Melpomene, aunque también hay otros motivos. En esta línea citamos la del Museo Arqueológico Provincial de León $-\mathrm{n} .^{\circ}$ inventario 670 (vv. AA., 1990: 272)-, la de Iptuci conservada en el Museo de Cádiz -n. ${ }^{\circ}$ inventario 1992- y las dos recuperadas en los Torreones, El Salobral (Abascal y Sanz, 1993). Especial interés por contar con un contexto estratigráfico preciso tienen otras dos piezas: la hallada en el vicus occidental de Córdoba, recuperada en un contexto de fines del s. III, cuya fabricación se sitúa en los ss. I o II (González y Moreno, 2005: 77); y la procedente de Baelo Claudia, recuperada en un contexto de los ss. I-II d. C. (Pozo, 1997: 222 y ss.; González y Moreno, 2005: 74).

Los paralelos de lucernas plásticas de bronce en la Península Ibérica son escasos. Hay tres lucernas plásticas portuguesas que se asemejan formalmente a la complutense: con rostro humano sobre el infundibulum, pie anular, asa más o menos compleja y rostrum diferenciado. Nos referimos a la de $S$. Cosme do Vale, la de Torre de Palma y la de Dine (Nunes, 2002: 246 y ss., est. 101-103). De ellas, la segunda, datada en época de Augusto, es la más semejante, también con una máscara de comedia (Nunes, 2002: 247 y est. 102), aunque la resolución de la escultura es mucho más elemental. 
Existe además alguna lucerna plástica más en territorio actualmente español, pero se aleja del concepto clásico ya que han sido diseñadas con un depósito de tendencia esférica, que concentra la parte modelada. Así, por ejemplo, es la hallada en Regina y conservada en el Museo Arqueológico Provincial de Badajoz, datada en el s. Iv d. C. (vv. AA., 1990: 278; Nogales, 1983: 40). Con forma de paloma, su factura es bastante elemental y está reforzada con incisiones posmoldeo; su base se resolvió con prótomos de patas y carece de asa, habiéndose concebido para ser suspendida de una única cadenita. Hay otra lucerna similar procedente de Andelos (Erice, 1986: 198, lám. III; VV. AA., 1990: 277), en forma de piña

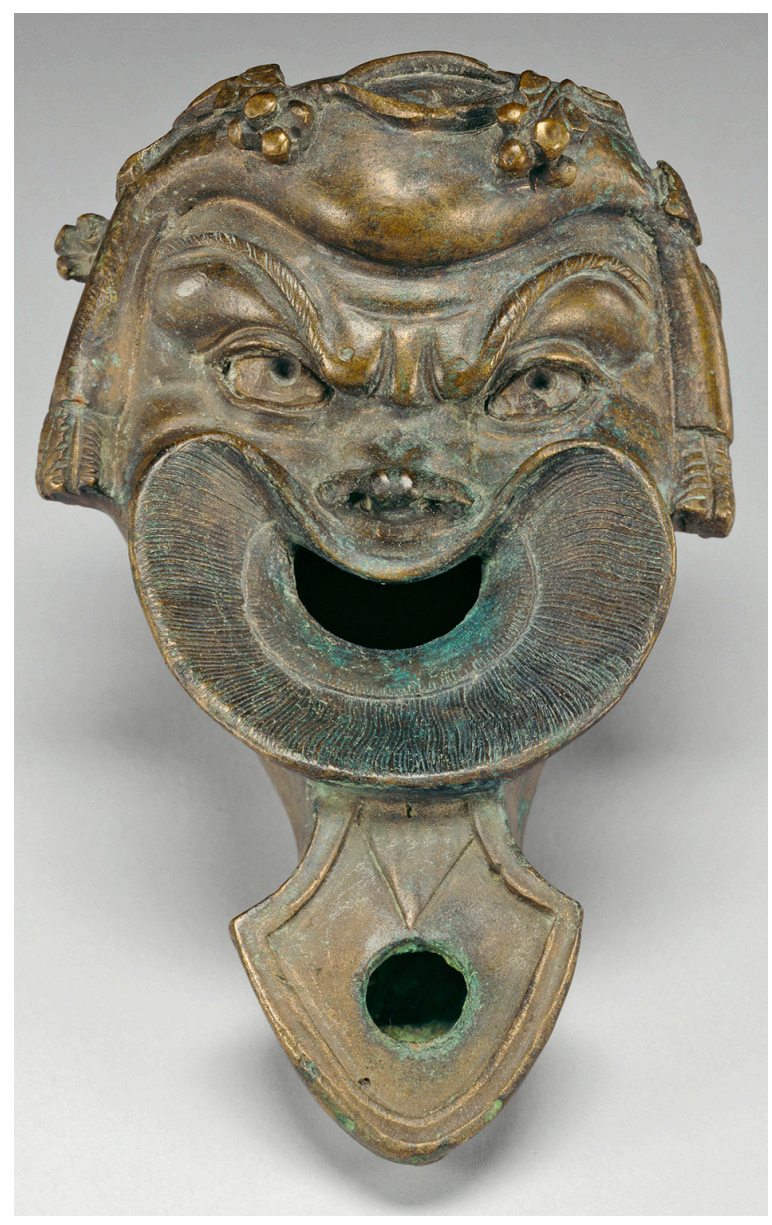

FIG. 12. Lucerna plástica de bronce representando un esclavo pícaro de la Comedia Nueva (imagen cortesía del J. Paul Getty Museum, Getty Open Content). y de canal abierto. Finalmente, citamos la hallada en el Coto de Altamiara, conservada en el Museo de Pontevedra (Filgueira y García, 1955: 135; vv. AA., 1990: 214), con cabeza de negro de muy bajo relieve y un rostrum formal.

Por otra parte, integradas en colecciones antiguas, de origen incierto -es decir, desconocemos si se recuperaron en contextos hispanos-, hay algunas lucernas excepcionales por su calidad. Citamos la lámpara con forma de erote galopando sobre delfín depositada en el MAN de Madrid y procedente de la colección del Museo de Historia Natural (Blázquez, 1959: 163, fig. 11); aunque el motivo decorativo en esta es totalmente distinto y se diferencia en el rostrum, la pieza del MAN recuerda al 'esclavo listo' de la complutense en su acusada plasticidad. Una pieza excepcional, también en la colección del MAN de Madrid y procedente de la colección de la Biblioteca Nacional, es la lámpara que Blázquez (1959: 169, f. 29) describe como máscara de Océano y que, sin embargo, Thouvenot (1927: 87) había descrito anteriormente como una máscara trágica ${ }^{6}$. Esta lucerna presenta un detalle escultórico destacable, ya que, además de su complejidad compositiva $^{7}$, la máscara del 'esclavo listo' cubre el disco; en la del MAN se recurre a una geometría formal más compleja, con dos rostra de planta circular y con volutas que excepcionalmente se separan del cuerpo. En cuanto a su calidad escultórica y complejidad formal es, sin duda, el ejemplar en la Península Ibérica más semejante a la lucerna complutense.

Sin embargo, el paralelo más próximo a nuestra lucerna plástica hay que buscarlo fuera de Hispania. Hasta donde hemos sido capaces de rastrear, la pieza más semejante es la conservada en el J. Paul Getty Museum con la sigla 96.AQ.193 (Fig. 12). No proceden del mismo molde pero la concepción formal de la lucerna es muy próxima a la complutense: alto pie cóncavo y rostrum triangular diferenciado, aunque el asa, aparentemente fundida por separado al cuerpo principal, tiene una solución distinta,

6 Más detalles en http://ceres.mcu.es/pages/Main, n. ${ }^{\circ}$ inv. 9985 del MAN.

7 En la base hay dos medios leones y también tiene dos delfines y patas de cangrejo. 


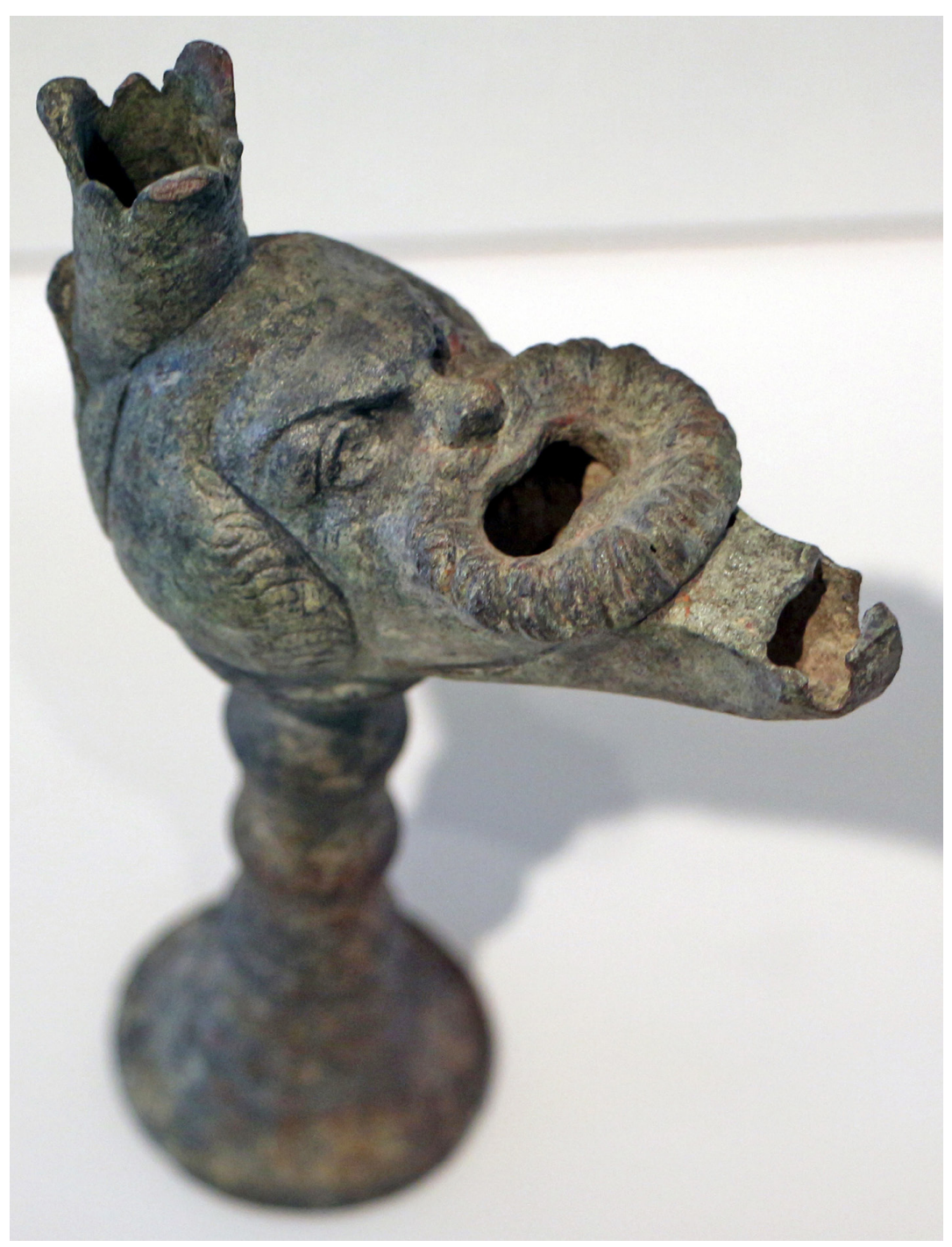

Fig. 13. Lucerna plástica de bronce del Museo Arqueológico Nacional de Aquileia representando un esclavo picaro de la Comedia Nueva (imagen tomada de https://commons.wikimedia.org/wiki/File:Lucerne_di_varia_forma_in_ bronzo,_et\%C3\%A0_imperiale,_06_maschera.jpg; acceso 30/08/2018).

su cronología se ubica entre fines del s. I e inicios del II d. C. (Bussière y Wohl, 2017: 626) ${ }^{8}$.

La máscara complutense es también relativamente similar a la de una lucerna que se encuentra en el Museo Arqueológico Nacional de Aquileia (Fig. 13). En este último caso, aunque el relieve presenta menor volumen, la representación escultórica mantiene cierta semejanza; sin embargo, el pie es excepcionalmente alto y el rostrum y la alimentación del infundibulum presentan soluciones totalmente distintas.

Muy parecida e interesante por su procedencia de un contexto datado es la lucerna hallada en Herculanum-incluso reconociendo la limitación documental propia de las excavaciones antiguas, ya que se encontró en 1746-. Está ilustrada en una lámina de la Antichitá di Ercolano (t. viII, lám. LXVII, n. ${ }^{\circ}$ 309) que representa un conjunto de objetos para iluminación junto con un lampadóforo (Fig. 14). Estudiada a partir de la documentación gráfica, Erice (2004: 215) incide en el carácter dionisiaco de la pieza y en su relación con la Comedia. Esta lucerna se distingue de la complutense principalmente por la ausencia de un rostrum diferenciado y por también con decoración escultórica, que en este caso se proyecta hacia atrás. La máscara es casi idéntica a la complutense, aunque carece de las orejas $y$, por tanto, de prótomos laterales para enganchar las cadenillas; en su lugar, aparece un tocado que, desde la frente, cae por los lados, de forma que se concibe solo como una lámpara autoportante, no para ser suspendida. La pieza carece de contexto arqueológico, pero su procedencia se sitúa en Italia y el asa, que allí es circular a diferencia de la ovoide complutense. Por lo demás, los otros aspectos formales y figurativos son muy semejantes.

No vamos a referirnos aquí detalladamente a las lucernas cerámicas con representaciones de

8 Cf. http://www.getty.edu/art/collection/objects /29629/unknown-maker-lamp-in-the-form-of-a-comicmask-roman-ad-75-125/?dz=\&artview $=\# 662$ c4d43815 0db38d8dbfbc2cceebd80325b93ff); acceso 18/08/2018. 
máscaras teatrales cómicas, que también existieron, aunque para Hispania se desconocen las de tipo plástico. Sin embargo, consideramos importante citar dos piezas: una es la 83.AQ.377.489, sorprendentemente bien conservada en el J. Paul Getty Museum (Bussière y Wohl, 2017: 594), muy semejante, incluso en sus dimensiones, al bronce que guarda esta misma institución, salvando la disparidad en la materia prima. Esta lucerna también carece de contexto arqueológico contrastable, aunque el museo indica su procedencia de Asia Menor y la fecha en el s. I d. C.; esa datación es coherente con su tipología, asimilable a las lucernas de volutas -y aunque las volutas de este rostrum se distingan con dificultad-. La otra es una lucerna cerámica semejante depositada en el Museo Arqueológico de Nápoles, que puede rastrearse en una imagen de archivo $^{9}$ documentando una exposición de los últimos años del s. XIX o principios del $\mathrm{xx}$ -Archivo Sommer, n. ${ }^{\circ} 11180-$. En este caso, sin embargo, la lucerna presenta tres rostra que, en nuestra opinión, deben interpretarse más como la imagen de un sátiro que como una máscara teatral, sobre todo, considerando las características orejas grandes y picudas que presenta. En cualquier caso, ambas producciones parecen ser variantes

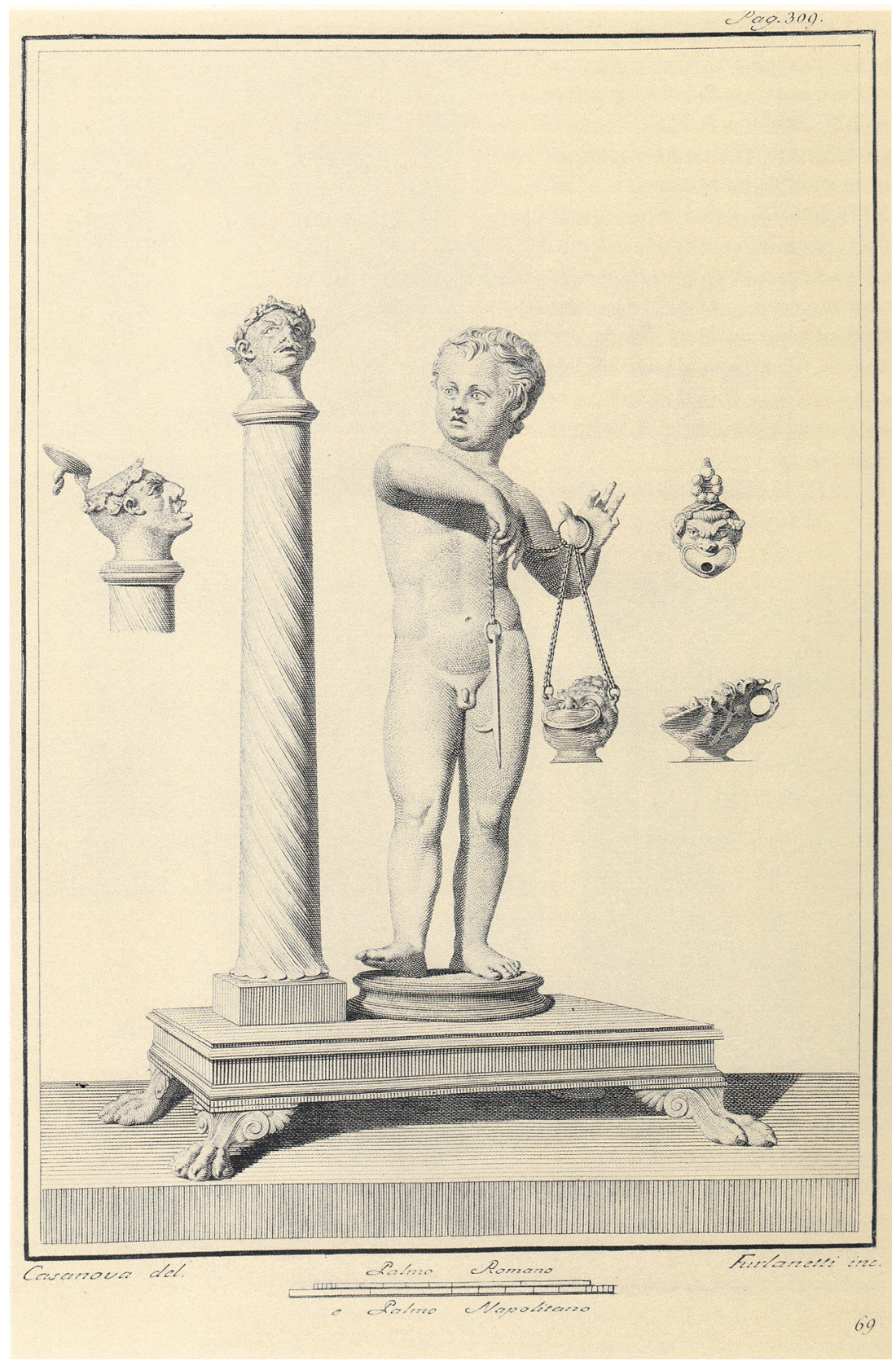

FIG. 14. Lámina de las Antichità di Ercolano representando un lampadóforo y varios objetos de bronce, entre ellos una lucerna con máscara teatral o sileno (según Rodriguez Zarzosa y Jiménez Salvador, 2004: t. VIII, lám. LXVII, 309).

9 Imagen disponible en https://upload.wikimedia. org/wikipedia/commons/8/81/Sommer\%2C_Giorgio_\% 281834-1914\%29_-_n._11180_-_Napoli_-_Museo_Nazionale.jpg; acceso 29/08/2018. baratas de sus referentes metálicos, quizás tratando de atender una demanda culturalmente idéntica, pero con menor poder adquisitivo.

Existe un consenso generalizado en fechar la producción de lucernas plásticas de bronce en general 
y las de 'esclavos listos' en concreto en el s. I o primera mitad del II, aunque se reconoce por parte de la mayoría de los investigadores la dificultad de las dataciones por criterios estilísticos y la complejidad de relacionar las tipologías de estos bronces -ya de por sí cuestionadas- con periodos concretos. Sin embargo, esta cronología está avalada por la procedencia de algunos de estos bronces de contextos bien datados como, por ejemplo, los de la bahía de Nápoles y también los de Vindonissa (Pozo, 1997: 204).

Otra cuestión a valorar es el tiempo de vida útil de estos objetos, que debió ser muy extenso, pues eran ajuares domésticos que a su utilidad en la vida cotidiana incorporaban el valor añadido de ser pequeñas obras de arte, seguramente muy valoradas en el mobiliario doméstico familiar, objetos de lujo que pasarían de generación en generación. El contexto estratigráfico de la lucerna complutense aporta un interesante dato arqueológico para reforzar esta teoría, pues la encontramos dispuesta para ser fundida en un momento no anterior a la segunda mitad del s. Iv, pero quizás incluso del v, lo que invita a pensar que probablemente habría estado en uso hasta esos momentos, considerada un pequeño tesoro familiar, y en todo caso una antigüedad. Este argumento de largos periodos de uso de estas piezas se refuerza en la estratigrafía a que pertenece la lucerna piriforme con máscara en el asa de Córdoba, que aparece lista para su amortización en un nivel del s. III.

También es problemático localizar los talleres donde se produciría este tipo de objetos. La hipótesis tradicional ha venido proponiendo un único y gran centro de fabricación para el s. I y parte del II, ubicado quizás en Capua a raíz de la demostrada relevancia que tuvieron las manufacturas de bronce en esa zona y su exportación a provincias (Pozo, 1997: 204 y ss.). Sin embargo, de una cronología aproximadamente similar, se han reconocido talleres menores de bronce en la bahía de Nápoles: así, por ejemplo, el situado junto a la puerta del Vesubio de Pompeya, especializado en vajillas de bronce (De Carolis, 1999: 193). Por ello resulta lógica la propuesta de que en esta región pudieron existir

(C) Universidad de Salamanca otros talleres menores de broncistas (Erice, 2004: 215), incluidos los que estuvieran especializados en objetos de iluminación, aunque hasta el momento no se haya podido constatar.

\section{Conclusiones}

La lucerna plástica con máscara de 'esclavo listo' de Complutum es una pieza excepcional que representa detalladamente, en un objeto de uso cotidiano, a un personaje característico de la cultura popular de los ss. I y II d. C. Se trata, además, de un objeto de extremada rareza tanto en el ámbito provincial hispano como en el imperial romano que cuenta exclusivamente con dos paralelos claros desde el punto de vista tipológico e iconográfico: el procedente de Herculano, solo documentado bibliográficamente, y otro actualmente conservado en el J. Paul Getty Museum de California, aunque también de origen suritálico.

Existe un claro consenso en que su fabricación se sitúa en el s. I o en la primera mitad del s. II d. C. en talleres de Campania, quizás realizada por artesanos con una reducida producción.

En nuestro caso la lucerna ofrece el interés añadido de contar con un contexto arqueológico preciso que permite proponer, recordando también el ejemplar de lucerna de bronce recuperado en Córdoba, también con contexto arqueológico, su valoración dentro de la categoría de pequeñas obras de arte transmitidas de una a otra generación, incluso con un valor añadido no solo de recuerdo familiar, sino también como antigüedad. Así se justificaría que la pieza complutense hubiera estado en uso hasta el s. IV y la cordobesa hasta el s. III.

Ese mantenimiento en uso de materiales de elevada calidad en su manufactura y que se mueven en los parámetros estéticos romanos más clásicos resulta acorde con materiales de otra naturaleza -mosaicos, pinturas murales, glíptica, escultura- recuperados en labores arqueológicas en Complutum, fechables a lo largo de toda la época imperial, que certifican el fuerte carácter de ciudad romana de esta urbe.

Zephyrus, LXXXIV, julio-diciembre 2019, 207-223 


\section{Bibliografía}

Abascal, J. M. y Sanz, R. (1993): Bronces antiguos del Museo de Albacete. Albacete.

Aurrecoechea, J. (2009): "Vajilla metálica de época romana en la región central de Hispania (actuales cc. AA. de Madrid y Castilla-La Mancha)", Sautuola, xv, pp. 327-348.

Bailey, D. M. (1996): A Catalogue of the Lamps in the British Museum. IV - Lamps of Metal and Lampstands. London.

BLÁzquEZ, J. M. (1959): ”Veintinueve lámparas romanas de bronce del Museo Arqueológico Nacional de Madrid", Zephyrus, 10, pp. 159-170.

Bussière, J. y Wohl, B. L. (2017): Ancient Lamps in the J. Paul Getty Museum. Los Angeles: J. Paul Getty Museum.

Carandini, A. (dir.) (1977): L'instrumentum domesticum di Ercolano e Pompei nella primera eta imperiale. Roma.

Cargo, B. (2002): "Aplike u obliku kazalinih maski (Attachments in the shape of theatre masks)". Longae Salonae. Split, vol. I, pp. 368-369.

De Carolis, E. (1999): "Schede". En Ciarallo, A. y De Carolis, E.: Homo Faber. Natura, sciencia e técnica nell'antica Pompei (Catálogo de la exposición). Milano, pp. 115-220.

De Spagnolis, M. C. y De Carolis, E. (1988): Le lucerne di bronzo di Ercolano e Pompei. Soprintendenza Archeologica Di Pompei. Catálogo 2. Roma: Ministero per i Beni Culturali ed Ambientali.

Erice, R. (1986): "Bronces romanos en el Museo de Navarra", Trabajos de Arqueología Navarra, 5, pp. 195-235.

Erice, R. (2004): “Consideraciones sobre los útiles de iluminación y sus soportes, incluidos en el tomo viII de las Antichità di Ercolano". En Rodríguez Zarzosa, C. y Jiménez Salvador, J. L.: Bajo la cólera del Vesubio. Testimonios de Pompeya y Herculano en la época de Carlos III. Valencia, pp. 203-228.

FernÁNdeZ IbáŃEZ, C. (2007): "Bibliografía básica comentada sobre metalistería romana en España”. En Metalistería de la Hispania Romana. Sautuola, XIII. Santander, pp. 606-670.

Filgueira, J. y García AlÉN, A. (1955): "Materiales para la carta arqueológica de la provincia de Pontevedra: Paleolítico, Neolítico, cultura dolménica, Edad del Bronce, petroglifos, castros, protoibérico e ibérico, Roma, restos de baja romanidad, paleocristianos y suevos", El Museo de Pontevedra, 8, pp. 31-40.
Freitas-Magalhấes, A. (2017): Facial Action Coding System 2.0: Manual de Codificación Cientifica de la Cara Humana. Oporto: FeELab Science Books.

Fuentes, A. (1990): "Los bronces bajoimperiales en Hispania". En Los bronces romanos en España (Catálogo de la Exposición, 1990). Madrid: Ministerio de Cultura, pp. 117-136.

González Virseda, L. M. y Moreno, M. (2005): "Un hallazgo metálico del vicus occidental de la Colonia Patricia", Anales de Arqueología Cordobesa, 16, pp. 65-78.

Loeschere, S. (1919): Lampen aus Vindonisa. Ein Beitrag zur Geschichte van Vindonisa und des antiken Beleuch-tungswesens. Zurich.

Menzel, H. (1954): Antiken lampen in Rómish-Germanischen Zentralmuseum zu Mainz. Mainz.

Montero, I. (2015): "La vajilla metálica de Camino de Santa Juana en el contexto de la producción metalúrgica romana". En VV. AA.: Esperando tiempos mejores. Las ocultaciones romanas del s.V d.C. en Cubas de la Sagra, Comunidad de Madrid (Catálogo de la Exposición 2015-2016). Madrid: MAR, pp. 75-82.

Morillo, A. y Rodríguez Martín, G. (2009): "Lucernas hispanorromanas". En Bernal, D. y Ribera, A. (eds.): Cerámicas hispanorromanas. Un estado de la cuestión. Cádiz, pp. 407-428.

Nogales, T. (1983): "Bronces de Regina", Museos, 3, pp. 37-42.

Nunes, A. J. (2002): Bronzes figurativos romanos de Portugal. Lisboa.

Palol y Salellas, P. De (1970): "Necrópolis hispanorromanas del siglo iv en el valle del Duero. III. Los vasos y recipientes de bronce", Boletín del Seminario de Estudios de Arte y Arqueología, 36, pp. 205-236.

Pozo, S. (1997): "Lucernas antiguas en bronce de la Baetica. Ensayo de clasificación: tipología y cronología”, Boletin del Seminario de Estudios de Arte y Arqueologia, 63, pp. 203-251.

Rascón, S. y Sánchez Montes, A. L. (2017): "La ciudad romana de Complutum: nuevos datos, nuevas interpretaciones". En Actas del Congreso Vides Monumenta Vetera. Zona Arqueológica, 20. Alcalá de Henares: MAR, pp. 126-143.

Rodríguez Zarzosa, C. y Jiménez Salvador, J. L.: Bajo la cólera del Vesubio. Testimonios de Pompeya y Herculano en la época de Carlos III. Valencia.

Rovira, S.; Consuegra, S. y Montero, I. (1989): "Estudio arqueometalúrgico de los objetos de metal de la necrópolis visigoda del Camino de los Afligidos”. En Méndez, A. y Rascón, S.: Los visigodos en Alcalá de Henares. Alcalá de Henares, pp. 191-200.

Zephyrus, LXXXIV, julio-diciembre 2019, 207-223 
SÁnchez Montes, A. L. (2014): "Aportaciones al conocimiento de la casa privada romana en Espańa: La domus en la ciudad de Complutum". En Actas de las VIII Jornadas de Patrimonio Arqueológico en la Comunidad de Madrid. Madrid, pp. 171-182.

Thоuvenot, R. (1927): Catalogue des figurines et objets de bronze du Musée Archéologique de Madrid. I. Bronzes grecs et romains. Paris.
Valenza Mele, N. (1981): Catalogo delle lucerne in bronzo. Museo Archeologico Nazionale di Napoli. Rome.

VV. AA. (1990): Los bronces romanos en España. Catálogo de la Exposición (Madrid, 1990). Madrid: Dir. Gral. Bellas Artes. 
